\title{
Llosa, Mario Vargas. A orgia perpétua: Flaubert e Madame Bovary. Tradução de José Rubens Siqueira. Rio de Janeiro: Objetiva, 2015. 280 p.
}

\author{
Matheus Silva Vieira* \\ UniversidadeFederal do Ceará
}

Em "O ideal do crítico", Machado de Assis (2008) nos advertiu para desconfiarmos dos críticos literários movidos por “cegas adorações" (p. 43), uma vez que a afinidade exacerbada entre aquele que analisa e o objeto analisado poderia corromper a investigação crítica. Deste modo, nós leitores deveríamos buscar as análises daqueles críticos desinteressados pelo seu objeto de análise, ou cujo interesse fosse meramente profissional, pois os críticos, no entender de Machado (2008), devem se furtar às dependências dos gostos pessoais, que acabam pondo em evidência as suas paixões pessoais, em detrimento da objetividade e da imparcialidade, que são as bases da crítica literária.

Em La Orgía perpetua, Mario Vargas Llosa contraria os preceitos machadianos de crítico ideal. Vargas Llosa, enquanto crítico, não é desinteressado, muito menos distante dos seus objetos de análise, Gustave Flaubert e Madame Bovary. Llosa pratica uma crítica parcial e interessada, pois não esconde nem a sua admiração arrebata-

\footnotetext{
* Graduado em Letras pela Universidade Federal do Ceará (UFC). Atualmente, é aluno do mestrado em Literatura Comparada pelo Programa de Pós-graduação em Letras desta mesma Universidade.
} 
dora por Flaubert e nem e o seu inexorável amor por Emma Bovary. Mas se de início Llosa não segue a prescrição machadiana de imparcialidade crítica, o escritor peruano segue, ao menos, outro preceito do bruxo carioca: a de que o crítico deve conhecer a fundo a sua matéria de análise. Llosa visa adentrar nos recônditos mais profundos do romance de Flaubert, para buscar o que Machado de Assis (2008) chamava de "espírito do livro" (p. 43).

Publicado originalmente em 1975, La Orgía perpetua é o terceiro livro de crítica de Vargas Llosa; antes ele já havia escrito Bases para una interpretación de Ruben Darío $(1958)^{1}$ e García Márquez: historia de un deicidio ${ }^{2}$ (1971). Enquanto crítico, Vargas Llosa demonstra ser profundamente apaixonado pela literatura, pois essa seria para ele um "denominador comum da experiência humana" 3 . O escritor peruano crê que os romances liberam os homens das clausuras da ignorância, já que sem literatura o mundo seria alheio à civilidade, e os homens análogos aos bárbaros. E a ideia de que a literatura nos leva a refletir sobre problemas existenciais e sociais, e de nos mostrar os limites da mesquinhez humana, está presente em quase toda a obra de Vargas Llosa, desde seus romances, perpassando seus contos e peças teatrais, até chegar aos seus textos críticos.

É comum a crítica afirmar que La Orgía perpetua é uma das portas de entrada para os estudos flaubertianos, o que não deixa de ser uma verdade, mas essa obra também pode ser lida como um "confessionário crítico”, porque Vargas Llosa assume em várias passa-

\footnotetext{
${ }^{1}$ Trata-se do trabalho de conclusão de curso apresentada por Mario Vargas Llosa para a obtenção do título de bacharel em Humanidades, na Universidad Mayor de San Marcos, em Lima. Este trabalho foi publicado em 2001 pelo Fondo Editoral de la Universidad Mayor de San Marcos.

${ }^{2}$ LLOSA, Mario Vargas. García Márquez: historia de un deicidio. Barcelona: Seix Barral, 1971.

${ }^{3}$ LLOSA, Mario Vargas. Em defesa do romance. In: Revista Piauí, São Paulo, v.1, n. 37, p. 64-69, outubro 2009.
} 
gens do livro que Flaubert foi o seu maior mestre literário. Assim, La Orgía perpetua pode interessar tanto aos estudiosos da obra de Gustave Flaubert, quanto aos estudiosos de Vargas Llosa.

O livro está dividido em três partes. Na primeira, Vargas Llosa, em tom de confissão, descreve a sua relação com Emma Bovary, e as suas primeiras leituras do romance:

Desde las primeras líneas el poder de persuasión del libro operó sobre mí de manera fulminante, como un hechizo poderosísimo. Hacía años que ninguna novela vampirizaba tan rápidamente mi atención, abolía así el contorno físico y me sumergía tan hondo en su materia. A medida que avanzaba la tarde, caía la noche, apuntaba el alba, era más efectivo el trasvasamiento mágico, la sustitución del mundo real por el ficticio. Había entrado la mañana -Emma y Léon acababan de encontrarse en un palco de la Ópera de Rouen- cuando, aturdido, dejé el libro y me dispuse a dormir: en el difícil sueño matutino seguían existiendo, con la veracidad de la lectura, la granja de los Rouault, las calles enfangadas de Tostes, la figura bonachona y estúpida de Charles, la maciza pedantería rioplatense de Homais, $y$, sobre esas personas y lugares, como una imagen presentida en mil sueños de infancia, adivinada desde las primeras lecturas adolescentes, la cara de Emma Bovary. Cuando desperté, para retomar la lectura, es imposible que no haya tenido dos certidumbres como dos relámpagos: que ya sabía qué escritor me hubiera gustado ser y que desde entonces y hasta la muerte viviría enamorado de Emma Bovary (LLOSA, 2011, p. 16)

Este trecho é traduzido por José Rubens Siqueira da seguinte forma:

Desde as primeiras linhas, o poder de persuasão do livro agiu sobre mim de maneira fulminante, como um feitiço poderosíssimo. Fazia anos que nenhum romance vampiri- 
zava tão rapidamente minha atenção, abolia assim o entorno físico e me submergia tão profundamente no seu mundo. À medida que avançava a tarde, caía a noite, apontava o alvorecer, era mais eficiente o transbordamento mágico, a substituição do mundo real pelo fictício. Era já de manhã Emma e León tinham acabado de se encontrar em seu palco da ópera de Rouen - quando, aturdido, deixei o livro e me dispus a dormir: no difícil sono matutino continuavam existindo, com a veracidade da leitura, a granja dos Rouault, as ruas enlameadas de Tostes, a figura bonachona e burra de Charles, o maciço pedantismo rio-platense de Homais, e por cima dessas pessoas e lugares, como uma imagem pressentida em mil sonhos de infância, adivinhada desde as primeiras leituras adolescentes, o rosto de Emma Bovary. Quando acordei, para retomar a leitura, é impossível que não tenha tido duas certezas como dois relâmpagos: que já sabia o escritor que eu gostaria de ser e de que desde então e até a morte viveria apaixonado por Emma Bovary. (LLOSA, 2015, p. 15-16)

Podemos observar, inicialmente, que $A$ orgia perpetua está bem próxima do texto de partida. Essas confissões são de suma importância para compreendermos a relação entre Llosa, Flaubert e Emma Bovary, e de como essas influências podem ser percebidas nos romances do escritor peruano. Em entrevista a Luis Harss ${ }^{4}$, Llosa afirma que Flaubert o ensinou a interpretar e descrever a realidade, não apenas a interior, mas também a exterior, e, no entender de Llosa, é a partir da realidade exterior que se chega à realidade interior. É por meio desse entendimento da realidade que Vargas Llosa irá interpretar Emma Bovary na primeira parte do livro.

Llosa afirma que seu fascínio pela personagem reside no caráter binário de Emma diante da realidade vivida, pois se Emma é adúlte-

$\overline{{ }^{4} \text { HARSS, Luis. Los Nuestros. Buenos Aires: Alfaguara, }} 2013$. 
ra, ladra e mentirosa é porque não aceita os limites que a sociedade impõe às mulheres.

Emma quiere conocer otros mundos, otras gentes, no acepta que su vida transcurra hasta el fin dentro del horizonte obtuso de Yonville, y quiere, también, que su existencia sea diversa y exaltante, que en ella figuren la aventura y el riesgo, los gestos teatrales y magníficos de la generosidad y el sacrificio. La rebeldía de Emma nace de esta convicción, raíz de todos sus actos: no me resigno a mi suerte, la dudosa compensación del más allá no me importa, quiero que mi vida se realice plena y total aquí y ahora. (LLOSA, 2011, p. 21)

Na tradução de José Rubens Siqueira, temos o seguinte:

Emma quer conhecer outros mundos, outras pessoas, não aceita que sua vida transcorra até o fim dentro do horizonte obtuso de Yonville, e quer também que sua existência seja variada e excitante, que nela figurem a aventura e o risco, os gestos teatrais e magníficos da generosidade e do sacrifício. A rebeldia de Emma nasce dessa convicção, raiz de todos os seus atos: não me resigno a meu destino, a duvidosa compensação do além não me importa, quero que minha vida se realize plena e totalmente aqui e agora. (LLOSA, 2015, p. 20)

Ao comparar os trechos acima, observamos que a tradução de José Rubens Siqueira se ateve ao estilo claro e direto de Vargas Llosa. A rebeldia de Emma é uma luta contra uma sociedade machista, que cerceia a liberdade feminina. Assim, segundo Vargas Llosa, se Emma quiser subverter os padrões sexuais do seu tempo, não lhe resta escolha melhor do que adotar uma personalidade múltipla, variante conforme os diferentes momentos sociais em que ela estará inserida. Esse binarismo ocorre também com a Menina 
má, personagem de um dos romances de Vargas Llosa ${ }^{5}$, que para suportar o peso da existência precisa ser uma e várias ao mesmo tempo. Se, para a sociedade, elas, Emma Bovary e Menina má, precisam ser "belas, recatadas e do lar", para si elas são "belas, sonhadoras e da vida".

Em outro ensaio, "História secreta de um romance" ${ }^{6}$ - texto que é dedicado a Carlos Fuentes -, Vargas Llosa afirma que escrever um romance é semelhante a um strip-tease, já que o romancista desnuda sua intimidade perante seus leitores: experiências pessoais vividas e/ou sonhadas, suas angústias, seus demônios. É isso o que Llosa tentará fazer na segunda parte de La Orgía perpetua: esmiuçar o processo de escrita de Madame Bovary, trazendo aos leitores detalhes sobre o processo de composição do livro, e discutindo questões estruturais do romance. E é ainda nessa parte, que é a mais extensa do livro, que Llosa abordará o modo como funciona o romance flaubertiano a partir de suas múltiplas engrenagens, como por exemplo: tempo, personagens, narradores. Llosa analisará, entre outras coisas, o estilo indireto livre de Flaubert, que considera

El gran aporte técnico de Flaubert consiste en acercar tanto el narrador omnisciente al personaje que las fronteras entre ambos se evaporan, en crear una ambivalencia en la que el lector no sabe si aquello que el narrador dice proviene del relator invisible o del propio personaje que está monologando mentalmente. (LLOSA, 2011, p. 297).

Na tradução de José Rubens Siqueira encontramos:

A grande contribuição técnica de Flaubert consiste em aproximar tanto o narrador onisciente do personagem que as

\footnotetext{
${ }_{5}^{5}$ LLOSA, Mario Vargas. Travessuras da menina má. Tradução de Ari Roitman e Paulina Wacht. Rio de Janeiro: Objetiva, 2006.

${ }^{6}$ LLOSA, Mario Vargas. História secreta de um romance. In: A casa verde. 3.a. ed. Tradução de Remy Gorga, filho. Rio de Janeiro: Nova Fronteira, 1971.
} 
fronteiras entre ambos se evaporam, em criar uma ambivalência na qual o leitor não sabe se aquilo que o narrador diz provém do relator invisível ou do próprio personagem que está monologando mentalmente. (LLOSA, 2015, p. 239).

Aproximar o narrador dos personagens significou uma grande transformação na forma de narrar, e segundo Llosa, abriu caminho para o monólogo interior. Em certo sentido, Flaubert pode ser visto como precursor da modernidade, e é essa ideia que Vargas Llosa desenvolve na terceira parte de La Orgía perpetua, pois o autor peruano traçará um paralelo entre Flaubert e outros escritores, como Joyce e Brecht, e de como as técnicas usadas por Flaubert auxiliaram os processos de escrita desses escritores.

Se a literatura se cruza com a história, e se a arte está apoiada na vida para tirar matéria para suas ficções, por que a vida do teórico não se pode cruzar com a vida do seu objeto de estudo? As semelhanças entre Mario Vargas Llosa e Gustave Flaubert vão muito além das influências literárias do segundo sobre o primeiro. Por ironia, ou acaso, pontos da vida de Flaubert e de Vargas Llosa se encontram. Flaubert escapou por pouco de uma condenação penal, pois Madame Bovary foi acusada de defender o adultério. Vargas Llosa também sofreu sanções por um de seus livros, $A$ cidade $e$ os cachorros, que foi condenado à fogueira no colégio militar Leoncio Prado, em Lima. Segundo alunos e ex-alunos do colégio, que organizaram uma cerimônia para a queima do livro, a obra de Vargas Llosa atentava contra a moral dessa instituição de ensino, já que a rígida disciplina desse colégio é ridicularizada no romance. A história se repetiu para Llosa, não como uma quase tragédia, como foi com Flaubert, mas como farsa, já que anos depois, em 2011, um ano depois de receber o prêmio Nobel de Literatura, Vargas Llosa foi homenageado no mesmo colégio.

Vargas Llosa é dono de uma extensa obra literária, que inclui romances, contos, peças teatrais e ensaios críticos. Dentre os seus 18 
romances publicados, podemos destacar $A$ cidade e os cachorros $^{7}$ (1963), A casa verde 8 (1966), Conversa na catedral $^{9}$ (1969) e $A$ guerra do fim do mundo ${ }^{10}$ (1981). Llosa ainda obteve importantes prêmios literários, como o Cervantes (1994) e o Nobel de Literatura (2010).

Muita coisa se passou na vida de Vargas Llosa; o escritor deixou de ser militante de esquerda e de simpatizar com Fidel Castro e com Cuba, com quem hoje troca farpas e acusações constantes, e passou a apoiar o liberalismo econômico como a única forma válida de democracia. Mas parece que até hoje uma das únicas coisas que ainda não mudaram em sua vida foi o seu amor por Flaubert e Emma Bovary, e é por isso que a nova tradução de $A$ orgia perpétua para o português, realizada por José Rubens Siqueira, não precisou nem de uma nota à edição brasileira, nem de acréscimos ou supressões provenientes de mudanças de opiniões do autor.

A tradução de José Rubens Siqueira é de 2015, e é a segunda tradução de $A$ orgia perpétua no Brasil. A tradução anterior é de Remy Gorga, filho, de 1979. As duas traduções guardam idiossincrasias que as distinguem entre si. Por $A$ orgia perpétua se tratar de um livro de crítica literária e não de ficção, encontramos um texto em que Vargas Llosa não explora tanto os recursos estilísticos da língua espanhola, mais especificamente do espanhol "callejero" peruano, como o faz em livros como As cidades e os cachorros. Ao cotejar as duas traduções brasileiras com o texto de partida, percebemos algumas diferenças. Gorga,

${ }^{7}$ LLOSA, Mario Vargas. A cidade e os Cachorros. Tradução de Samuel Titan Jr. Rio de Janeiro: Objetiva, 2013.

8 Fronteira, 1971.

A casa verde. 3.a. ed. Tradução de Remy Gorga, filho. Rio de Janeiro: Nova 9 1977. . Conversa na catedral. Tradução de Olga Savary. São Paulo: Círculo do Livro, 10 . A guerra do fim do mundo. Tradução de Paulina Wacht e Ari Roitman. Rio de Janeiro: Objetiva, 2010.

Cad. Trad., Florianópolis, v. 37, $n^{0}$ 2, p. 338-348, mai-ago 2017 
por exemplo, usa notas de rodapé quando esbarra em problemas de tradução, como é o caso da palavra "huachafería". Tomemos como exemplo o trecho no qual a palavra se encontra. No texto de partida temos o seguinte:

Cada país, clase social, generación introduce variantes y aportes a la cursilería (en el Perú se la llama huachafería y es uno de los dominios en el que los peruanos hemos sido realmente creativos), una de las expresiones humanas más persistentes y universales. (LLOSA, 2011, p. 29)

Na tradução de Remy Gorga:

Cada país, classe social, geração introduz variantes e contribuições ao ridículo (no Peru chamam-na de huachafería, que é um dos domínios no qual nós os peruanos temos sido realmente caritativos), uma das expressões humanas mais persistentes e universais. (LLOSA, 1979, p. 21).

Gorga mantém o termo "huachafería", porém traz uma nota de rodapé explicando que se trata de um peruanismo aceito pela Real Academia Espanhola e que equivale a "cursilería", que ele traduz por "ridículo". Já na tradução de José Rubens Siqueira temos:

Cada país, classe social, geração introduz variantes e contribuições à vulgaridade (no Peru se chama huachafería e é um dos domínios em que nós, peruanos, temos sido realmente criativos), uma das expressões humanas mais representativas e universais. (LLOSA, 2015, p. 25)

Siqueira não traz nenhuma nota de rodapé, e traduz "cursilería" por "vulgaridade". Podemos perceber que os dois tradutores optaram por manter "huachafería" no texto de partida, traduzindo apenas "cursilería". "Huachafería" pode designar tanto o "ridículo" quanto o "vulgar", embora stricto sensu esteja mais próximo do 
primeiro do que do segundo, e, em linhas gerais, corresponderia em português brasileiro a "breguice" ou a "cafonice".

Gorga, talvez por ter traduzido nos fins dos anos 80, opta por um uso maior de ênclises ("chamam-na), já Siqueira prefere as próclises ("se chama"). A escolha vocabular também diferencia e marca o recorte temporal nas duas traduções. Enquanto Gorga traduz palavras como "mudas de narrador" (p. 139), "fealdade" e "arte depurada e estranha" (p. 179); Siqueira prefere "mudanças de narrador" (p. 212), "feiura" e "arte depurada e requinta$d a "$ (p. 252).

Parafraseando Llosa, cada geração introduz variadas contribuições à tradução. Como percebemos, as duas traduções são produtos de épocas distintas, e como nos lembra Borges (1998), embora épocas diferentes produzam diferentes traduções de uma mesma obra, essas traduções não são superiores nem inferiores entre si, pois todas guardam idiossincrasias do período em que foram traduzidas, mas lembra o escritor argentino a tradução mais agradável de se ler é, em geral a que está temporalmente mais próxima de nós. Borges (1998) também lembra que as diferentes traduções para uma mesma língua engradecem a leitura dos textos, pois possibilita que o leitor tenha contato com diferentes versões de um mesmo texto. Assim, a nova tradução de $A$ orgia perpétua é mais uma possibilidade para que o leitor brasileiro tenha contato com a obra crítica de Mario Vargas Llosa, e que essa leitura possa abrir os olhos dos leitores para os grandes escritores da América Hispânica, que além de grandes ficcionistas foram exímios ensaístas, como é o caso de Jorge Luis Borges, Octavio Paz, Julio Cortázar e Carlos Fuentes.

Ao comparar a tradução com La orgía perpetua, percebemos que José Rubens Siqueira foi um leitor cuidadoso do texto de partida. Este tradutor possui familiaridade com a obra de Vargas Llosa, 
pois já traduziu um de seus livros para o português, Tia Julia $e$ o escrevinhador ${ }^{11}$.

\section{Referências}

ASSIS, Machado de. O ideal do crítico. Organização de Migues Sanches Neto. Rio de Janeiro: José Olympio, 2008.

BORGES Jorge Luis. As Versões Homéricas. In: . Obras completas.

Vários tradutores. São Paulo: Globo, 1998. v. 1.

LLOSA, Mario Vargas. La orgía perpetua: Flaubert y Madame Bovary. Madrid: Santillana-punto de lectura, 2011.

. A orgia perpétua: Flaubert e Madame Bovary. Tradução de Remy Gorga, filho. Tradução dos trechos em francês de Piero Angarano. Rio de Janeiro: F. Alves, 1979.

Recebido em: 07/10/2016

Aceito em: 08/01/2017

Publicado em maio de 2017

${ }^{11}$ LLOSA, Mario Vargas. Tia Julia e o escrevinhador. Tradução de José Rubens Siqueira. Rio de Janeiro: Objetiva, 2007. 